\title{
Validação de aspectos semânticos em diretrizes para elaboração de Materiais Educativos Impressos para Promoção da Saúde: contribuição do Design da Informação
}

Semantic aspects validation in guidelines for the elaboration of Printed Educational Materials for Health Promotion: contribution of Information Design

Ranielder Fábio de Freitas, Hans da Nóbrega Waecheter, Solange Galvão Coutinho \& Fabiane do Amaral Gubert

design da informação, validação de conteúdo, materiais educativos impressos, promoção da saúde

\footnotetext{
O presente estudo teve como objetivo validar o conteúdo de um Guia para Elaboração de Materiais Educativos Impressos para Promoção da Saúde, por juízes nas áreas do Design da Informação e Design Gráfico. Para a validação do conteúdo participaram do estudo sete juízes, selecionados via Plataforma Lattes, os quais analisaram o material a partir de aspectos semânticos. A partir das considerações dos juízes, desenvolveuse um quadro sinóptico que serviu como um norteador dos aspectos apreciados, adaptados da Linguagem Visual de Horn (1998). Para consenso do julgamento dos juízes utilizou-se o índice de validade de conteúdo (IVC). Após a validação dos itens o Guia apresentou IVC maior que 0,78, considerado padrão ouro. Dessa forma, foi possível propor um guia adequado com linguagem visual acessível voltado para profissionais da saúde. Ao final, o método de validação de conteúdo proposto para o Guia, mostrou-se confiável para identificação de fragilidades e elaboração do material. Os comentários/sugestões elencados pelos juízes foram relevantes e fortaleceram as representações imagéticas no decorrer do conteúdo, a partir de orientações válidas acerca da disposição dos elementos na página.
} 
information design, content validation, printed educational materials, health promotion
The present study aimed to validate the content of a Guide for the Development of Printed Educational Materials for Health Promotion, by judges in the areas of Information Design and Graphic Design. For content validation, seven judges participated in the study, selected via the Lattes Platform, who analyzed the material from semantic aspects. Based on the judges' considerations, a framework was developed that served as a guide for the aspects appreciated, adapted from Horn's Visual Language (1998). For consensus of the judges' judgment, the content validity index (CVI) was used. After validating the items, the Guide presented a CVI greater than 0.78 , considered the gold standard. Thus, it was possible to propose an appropriate guide with accessible visual language aimed at health professionals. In the end, the content validation method proposed for the Guide, proved to be reliable for identifying weaknesses and preparing the material. The comments/suggestions listed by the judges were relevant and strengthened the image representations throughout the content, based on valid guidelines about the layout of the elements on the page.

\section{Introdução}

Atualmente verifica-se a publicação e divulgação de uma diversidade de Materiais Educativos Impressos (MEIs) com foco na Promoção da Saúde e prevenção de doenças. Destes MEIs produzidos, destaca-se os manuais, cartilhas, folderes, álbuns seriados e diversos materiais que são capazes de divulgar informações que podem contribuir para mudanças no estilo de vida da população. É neste contexto, de construção de MEIs, que os profissionais de saúde têm utilizado de abordagens compositivas na elaboração de artefatos visuais como estratégia para mediação de informações.

Para Twyman $(2002,1979)$, uma composição deve compreender a utilização e manipulação de elementos gráficos, preferencialmente por especialistas na área, que favorecem a configuração desses produtos em determinado contexto. Em outras palavras, é desejável que um designer, em especial o Info Designer, participe do processo relacional entre os componentes configurativos envolvidos, para que dubiedades informacionais e subjetividades sejam minimizadas.

O panorama projetual e proposta de diretrizes para elaboração de MEIs na área da saúde (feitas por profissionais da saúde) tem sido frequente e tende à ampliação, visto a complexidade abordada. Porém, observa-se escassez de estudos que favoreçam a troca de saberes entre as áreas para a elaboração destes materiais. Embora existam estudos que apresentem iniciativas de aproximação entre saúde e o design , estas são geralmente produzidas internacionalmente (Freitas, 2017). Sobre isso, Lopes, Barbosa \& Coutinho (2012) comentam que pesquisas articuladas a processos interventivos de design, em destaque aquelas que se estabelecem junto à não-especialistas da área, devem ser fortalecidas. 
As produções oriundas dos profissionais de saúde geralmente têm como fundamentação teórica elementos da Educação e Comunicação em Saúde, estes considerados relevantes para a produção dos MEIs. No entanto esta produção poderia ser potencializada com apoio do campo do design, na medida em que o conhecimento da profissão ampliaria a interpretação das informações produzidas, junto a população a qual se destina.

Dessa forma, o presente estudo teve como objetivo validar o conteúdo de um Guia para Elaboração de Materiais Educativos Impressos para Promoção da Saúde, por juízes nas áreas do Design da Informação e Design Gráfico. O Guia produzido teve como público alvo profissionais da saúde e abordou aspectos semânticos.

Na pesquisa o conceito de validade é abordado como o grau em que uma proposta, neste caso o Guia, mostra-se apropriada para mensurar ou alcançar o público ao qual se destina. Assim, quando se submete um material ao procedimento de validação, é verificado se o Guia proposto consegue alcançar seu objetivo. Ao final o estudo pode contribuir na elaboração de MEIs a partir de diretrizes válidas e confiáveis que facilitam a mediação das informações, a partir do olhar e experiências dos juízes participantes e necessidades do público pretendido.

\section{Processo Metodológico}

Estudo metodológico, realizado em 2017, com foco na validação de juízes na área do Design da Informação e Design Gráfico. O ensaio faz parte de um estudo maior no qual realizou-se a construção de um Guia para Elaboração de Materiais Educativos Impressos para Promoção da Saúde (Freitas, 2017). A amostra do estudo foram 7 juízes da área do Design.

Pasquali (2010) comenta que a validação verifica e adequa a representação de atributos por meio da avaliação de juízes, ou seja, permite apresentar a confiabilidade do material por meio de julgamento e critérios pré-definidos.

Os critérios de classificação/inclusão dos juízes, seguiu a pontuação descrita no Quadro 1, elaborada pelo autor e com apoio nos pressupostos de Pasquali (2010). A busca ocorreu na Plataforma Lattes e contou com aqueles que atingiram uma pontuação mínima de 5 pontos. 


\begin{tabular}{|l|l|}
\hline Critérios de classificação de Juízes & Pontuação \\
\hline Ser doutor & $4 p$ \\
\hline $\begin{array}{l}\text { Possuir tese na área do design gráfico/design da informação ou de saúde (elaboração de } \\
\text { MEls e validação de conteúdos). }\end{array}$ & $2 p$ \\
\hline $\begin{array}{l}\text { Ser mestre } \\
\text { Possuir dissertação na área design gráfico/design da informação ou de saúde (elaboração } \\
\text { de MEls e validação de conteúdos). }\end{array}$ & $3 p$ \\
$\begin{array}{l}\text { Possuir artigo publicado/resumo em anais de evento na área do design gráfico/design da } \\
\text { informação ou de saúde (elaboração de MEls e validação de conteúdos). }\end{array}$ & $1 p$ \\
$\begin{array}{l}\text { Possuir prática profissional de no mínimo três anos na temática na área do design } \\
\text { gráfico/design da informação ou de saúde (elaboração de MEls e validação de conteúdos). }\end{array}$ & $2 p$ \\
Participar de grupo/projeto que envolve o tema (1pt) & $1 p$ \\
\hline Ter experiência docente em disciplina que envolve o tema (1pt) & $1 p$ \\
\hline
\end{tabular}

Quadro 1 Sistema de Classificação de Juízes segundo critérios próprios. Fortaleza, 2017. Fonte: Do autor.

No estudo foi verificada a validação semântica, a qual teve como objetivo a verificação do conteúdo para minimização de dubiedades pelo público-alvo. É sabido que as percepções entre juízes e o público do Guia podem variar, devido a abrangência e complexidade de cada área ou mesmo sua experiência em desenvolvimento de MEIs, não sendo coerente tratar que são olhares necessariamente intercambiáveis. No entanto, as recomendações postas do Guia servem como um direcionamento, onde cada profissional irá fazer as adequações necessárias à sua realidade (Alexandre, Coluci, 2011).

No que se refere as percepções dos juízes sobre os aspectos de semântica, foi utilizado o Índice de Validade do Conteúdo (IVC). O IVC mede a concordância entre as opiniões dos juízes e deve ser igual e/ou superior a 0,78 (Polit; Beck, 2011). Esse método emprega a utilização de escala tipo Likert com pontuação de um a quatro com quatro níveis de resposta, sendo: 1-Inadequado, 2- Parcialmente adequado, 3- Adequado, 4- Totalmente adequado, conforme observa-se no Quadro 2. 


\begin{tabular}{|c|c|c|c|c|c|}
\hline \multirow{2}{*}{ Ref. } & \multicolumn{5}{|c|}{ ado; 4- Totalmente adequado } \\
\hline & & & & & \\
\hline 1 & $\begin{array}{l}\text { O processo metodológico para desenvolvimento de MEls proposto } \\
\text { é relevante e de simples compreensão. }\end{array}$ & 1 & 2 & 3 & 4 \\
\hline 2 & $\begin{array}{l}\text { O capitulo sobre o uso textos, contribui para conhecimentos } \\
\text { introdutórios à manipulação dos atributos dos elementos textuais } \\
\text { na elaboração de MEls. }\end{array}$ & 1 & 2 & 3 & 4 \\
\hline 3 & $\begin{array}{l}\text { O capitulo sobre o uso de imagens, favorece conhecimentos } \\
\text { básicos para a representação de contextos através de imagens na } \\
\text { elaboração de MEls. }\end{array}$ & 1 & 2 & 3 & 4 \\
\hline 4 & $\begin{array}{l}\text { A representação de expressões através dos cartoons, proporciona } \\
\text { identificação pelos usuários de situações e contextos que } \\
\text { envolvam emoções. }\end{array}$ & 1 & 2 & 3 & 4 \\
\hline 5 & $\begin{array}{l}\text { O capítulo sobre o uso textos e imagens, proporciona noções da } \\
\text { relação semântica entre o uso de textos e imagens em conjunto. }\end{array}$ & 1 & 2 & 3 & 4 \\
\hline 6 & $\begin{array}{l}\text { O capitulo sobre o uso de esquemas gráficos, esclarece } \\
\text { conhecimentos básicos e representa o uso de textos, imagens e } \\
\text { outros simbolos visuais, tal como Pictogramas Não-Sequenciais } \\
\text { (PNSs) e Sequências Pictóricas de Procedimento (SPPs), para } \\
\text { contextos diversos. }\end{array}$ & 1 & 2 & 3 & 4 \\
\hline 6.1 & $\begin{array}{l}\text { O processo metodológico para desenvolvimento de SPPs é } \\
\text { relevante e de simples compreensão. }\end{array}$ & 1 & 2 & 3 & 4 \\
\hline 6.2 & $\begin{array}{l}\text { A representação de partes do corpo humano/objetos, seccionados } \\
\text { ou inteiriços, possuem representação adequada e de simples } \\
\text { compreensão. }\end{array}$ & 1 & 2 & 3 & 4 \\
\hline 6.3 & $\begin{array}{l}\text { A manipulação dos elementos de conexão (linhas, setas e } \\
\text { quadros) utilizados nos PNSs e SPPs, contribuem para simples } \\
\text { compreensão. }\end{array}$ & 1 & 2 & 3 & 4 \\
\hline 7 & $\begin{array}{l}\text { O capitulo sobre princípios básicos de leiaute, contribui para } \\
\text { noçỗes da organização dos elementos de texto e imagens nas } \\
\text { páginas dos MEls. }\end{array}$ & 1 & 2 & 3 & 4 \\
\hline 8 & $\begin{array}{l}\text { A apresentação de diretrizes no final da cada capitulo (resumos), } \\
\text { promove um resgate simplificado dos princípios que devem ser } \\
\text { utilizados em cada contexto. }\end{array}$ & 1 & 2 & 3 & 4 \\
\hline
\end{tabular}

Quadro 2 Instrumento utilizado na verificação dos aspectos semânticos do Guia e escala likert do IVC- Juízes do Design. Fortaleza, 2017. Fonte: Do autor.

Ressalta-se que foi incorporado nesta pesquisa os quatro princípios da bioética: autonomia, beneficência, não-maleficência e justiça que norteiam a resolução 466/12 do Conselho Nacional de Saúde, para pesquisa envolvendo seres humanos, de forma direta ou indireta, sejam elas realizadas por qualquer categoria profissional (Brasil, 2012). O estudo foi aprovado pelo Comitê de Ética e Pesquisa da UFPE (CEPUFPE) CAAE 55430016.0.0000.5208.

\section{Resultados e Discussão}

Os 7 juízes participantes possuíam idade entre 28 a 51 anos, com predominância do sexo feminino (5), sendo 2 do sexo masculino, tendo experiência profissional na elaboração de MEIs que variava de 5 a 26 anos com titulação de doutorado (2) e mestrado (5). Vale ressaltar que um declarou possuir título de Pós-Doutorado.

Verifica-se que os 11 itens comentados pelos juízes a seguir (o item descrito na íntegra pode ser verificado no quadro 2), obtiveram pontuação no IVC igual ou superior a 0,78 , tendo o seu conteúdo devidamente validado. Destaca-se ainda que os quesitos 5, 6.1, 6.2 e 8, obtiveram IVC igual a 1 e não tiveram comentários dos juízes. Dessa forma, algumas considerações dos juízes serviram para adaptações no conteúdo, sendo apresentada as respectivas justificativas para as estratégias adotadas no Quadro 3. 


\begin{tabular}{|c|c|c|c|c|}
\hline \multicolumn{5}{|c|}{ FRAGILIDADES - SEMÂNTICA } \\
\hline Ref. & Item & Fragilidade identificada pelos juizes & $\begin{array}{c}\text { Estratégia/ação adotada pelo } \\
\text { pesquisador }\end{array}$ & $\begin{array}{l}\text { IVC } \\
\text { Final }\end{array}$ \\
\hline 1 & 1 & $\begin{array}{l}\text { - A representação verticalizada da } \\
\text { metodologia proposta pode dificultar o } \\
\text { entendimento da ideia de ser um } \\
\text { processo sempre em desenvolvimento; } \\
\text { - Na metodologia proposta, o contexto de } \\
\text { inserção deve considerar al ém do } \\
\text { entorno do usuário as circun stâncias de } \\
\text { uso do } \mathrm{MEl} \text {; }\end{array}$ & $\begin{array}{l}\text { - Foi criada uma re presentação de } \\
\text { processo cíclico, com visual menos } \\
\text { carre gado; } \\
\text { - As circunstâncias de uso foram } \\
\text { incluídas no item sobre Perfil do } \\
\text { Usuário; }\end{array}$ & 0,85 \\
\hline 2 & IV & $\begin{array}{l}\text { - Em partes do texto sobre tipografia, } \\
\text { alguns termos são utilizados e não são } \\
\text { explicados; família tipográ fica, teoria da } \\
\text { Gestalt, tipos de linguagem, etc. } \\
\text { - Complementar situações sobre uso de } \\
\text { cores nos textos; }\end{array}$ & $\begin{array}{l}\text { - Alguns termos passaram a integrar um } \\
\text { glossário sobre design no Guia, outros } \\
\text { foram retirados; } \\
\text { - Exemplos de contraste e significados } \\
\text { de cores foram adicionadas; }\end{array}$ & 0,85 \\
\hline 3 & $\mathrm{~V}$ & $\begin{array}{l}\text { - E necessário fazer indicações sobre o } \\
\text { redimensionamento de imagens e o que } \\
\text { a prática pode ocasionar, }\end{array}$ & $\begin{array}{l}\text { - In dicações incluídas no capítulo sobre } \\
\text { imagens; }\end{array}$ & 0,85 \\
\hline 4 & $\mathrm{VI}$ & $\begin{array}{l}\text { - O uso de cartoons para re presentar } \\
\text { populações é controversa e carece de } \\
\text { mais evidências científicas; }\end{array}$ & - Justificativas científicas adicionadas; & 0,85 \\
\hline 6 & VII & $\begin{array}{l}\text { - A sequência em linhas e o hábito } \\
\text { ocidental de ler da esquerda para a } \\
\text { direita e de cima para baixo parece ir } \\
\text { contra a lógica de leitura do exemplo } \\
\text { apresentado; }\end{array}$ & $\begin{array}{l}\text { - O exemplo foi suprimido, visto que o } \\
\text { primeiro se mostrou suficiente para } \\
\text { retratar o dito no texto; }\end{array}$ & 0,85 \\
\hline 6.3 & VIII & $\begin{array}{l}\text { - A figura de desenvolvimento de SPPs } \\
\text { poderia trazer um exemplo prático para } \\
\text { melhor ilustrar a compreen são da } \\
\text { metodologia; }\end{array}$ & $\begin{array}{l}\text { - O esquema gráfico original, foi } \\
\text { adaptado e expandido, trazen do mais } \\
\text { detalhes sobre o desenvolvimento de } \\
\text { SPPs; }\end{array}$ & 0,85 \\
\hline 7 & $\begin{array}{l}\mathrm{IX} \\
\mathrm{X}\end{array}$ & $\begin{array}{l}\text { - Acrescentar a definição de leiaute; } \\
\text { - Talvez não se deva indicar o que são } \\
\text { rios, órfãs, viúvas e dentes-de-cavalo, } \\
\text { basta indicar que não se deve deixar } \\
\text { uma única palavra na linha e assim por } \\
\text { diante; } \\
\text { - Indicar que o princípio de re petição } \\
\text { utilizado exaustivamente pode gerar } \\
\text { monotonia, por isso, atentar para os } \\
\text { diferentes conteúdos textuais e visuais } \\
\text { para refletir sobre possíveis variações de } \\
\text { apresentação. } \\
\text { - Os pontos apresentados são suficientes, } \\
\text { mas poderia ser adicionado um link de } \\
\text { interesse sobre o assunto para } \\
\text { complementar o conteúdo. }\end{array}$ & $\begin{array}{l}\text { - Acrescentan do à seção de glossário; } \\
\text { - Os termos foram alterados para } \\
\text { "linhas isoladas" e "palavras isoladas" } \\
\text { e adequados ao texto; } \\
\text { - In dicações e exemplos acre scentados; } \\
\text { - A intenção do Guia é dar orientações } \\
\text { gerais por meio de pontos fragilizados } \\
\text { identificados, acre dita-se que não seja } \\
\text { de interesse do conteúdo um } \\
\text { aprofundamento. Para isso indica-se } \\
\text { um profissional de design. }\end{array}$ & 0,85 \\
\hline
\end{tabular}

Quadro 3 Fragilidades semânticas apontadas pelos juízes e ação adotada pelo pesquisador. Fortaleza, 2017. Fonte: Do autor.

Um dos juízes destacou no item I, que a representação verticalizada do processo metodológico proposto poderia ser entendida como uma ação uniforme e sem possibilidades de comunicação entre as etapas de desenvolvimento, embora essa possibilidade tenha sido explicitada em forma de texto complementar, mas não estava clara no esquema metodológico. Esse ponto merece destaque porque o processo deveria dispor das etapas de desenvolvimento de um MEI com uma orientação esclarecida dos passos que devem ser adotados.

O esquema metodológico proposto no Guia o qual surgiu a partir da etapa e validação com juízes na área e aprofundamento do conteúdo pelo pesquisador, teve como fundamentação a classificação cíclica e com previsão de feedbacks de Munari (1981), onde o autor comenta que os retornos entre os resultados produzidos em cada etapa devam complementar as etapas anteriores caso seja necessário, de forma a acontecer uma retroalimentação de dados e informações que possibilitem uma validação das metas a serem atingidas pelo designer. Esse processo de idas e vindas é irrestrito, até que o designer ache que 
suas hipóteses atingiram uma saturação de informações necessárias para o lançamento do artefato em questão.

A releitura do esquema foi fundamentada no diagrama conceitual de Horn (1998) e previu um maior destaque visual na nomeação de cada etapa, assim como a eliminação dos quadros cinzas que causavam excesso de elementos na página. Além disso, a disposição das ações a serem realizadas durante o processo teve como intenção a leitura das orientações no sentido horário, e não mais de cima para baixo (Figura 1).

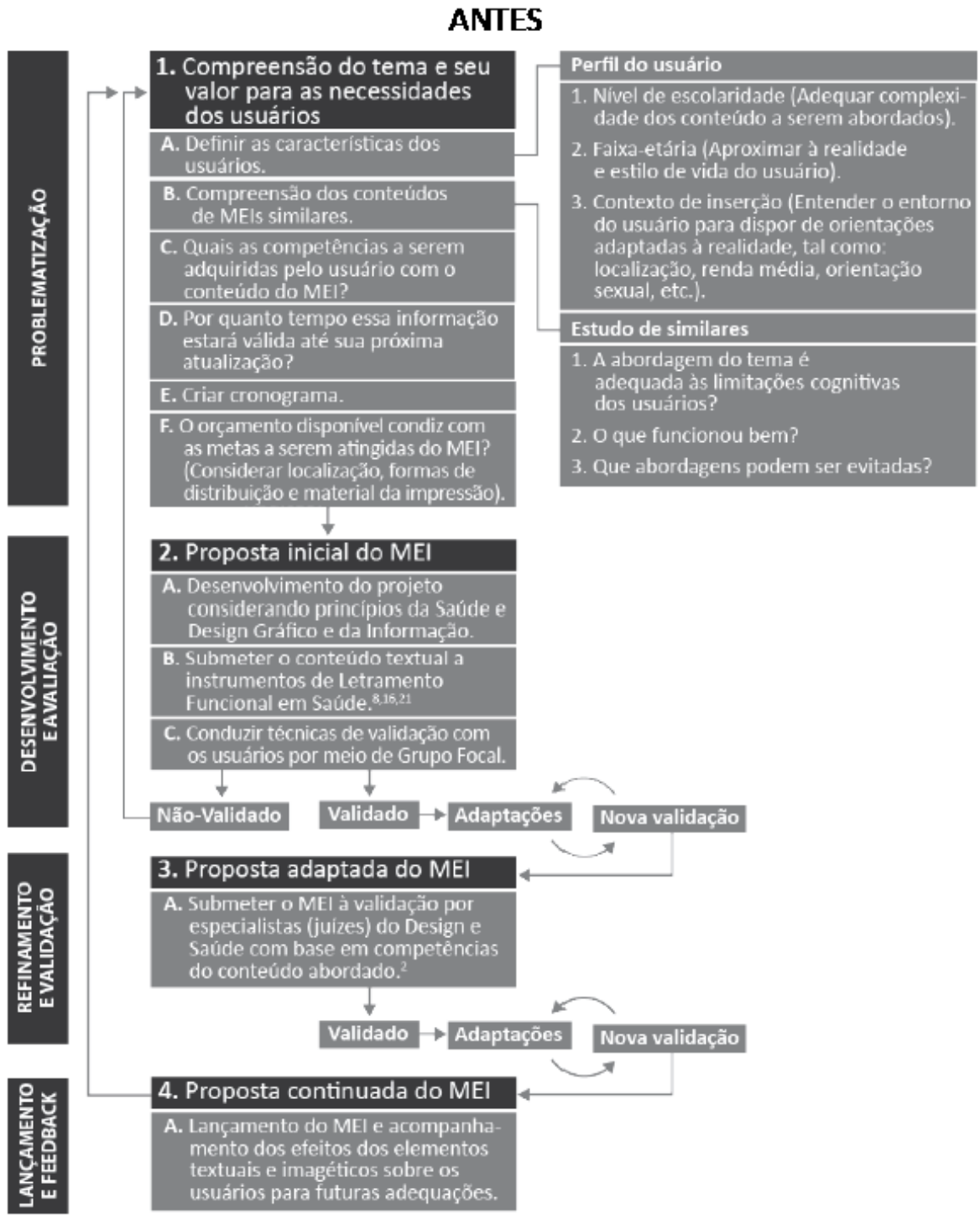


DEPOIS

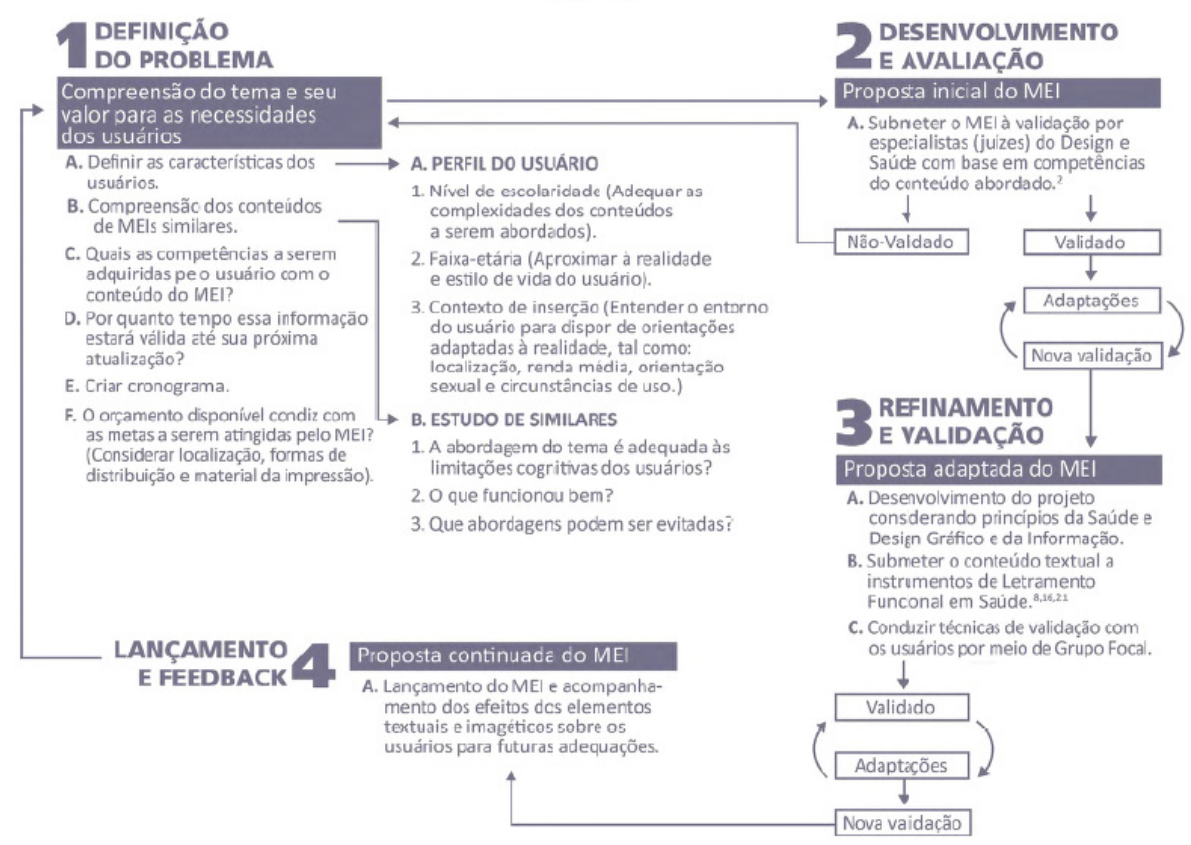

Figura 1 Comparação entre os esquemas metodológicos das duas versões do Guia. Fonte: Do autor.

Outrossim, no mesmo esquema (Item II) foi sugerido que as 'circunstâncias de uso' fossem consideradas no contexto de inserção do MEI, onde anteriormente estavam previstos que o entorno do usuário deveria ser composto por informações adaptadas à sua realidade. A sugestão foi acatada, pois como comenta Pettersson (2010), no desenvolvimento de um artefato deve-se assegurar a validade da informação e sua exposição em ambientes diversos, considerando fatores de iluminação e temporais.

No item III, foi indicado que estivessem presentes as definições dos vários termos de design utilizados no decorrer do Guia.

Considerando os pressupostos de Pettersson (2010b), a versão anterior esbarrava na fragilidade da percepção ao texto, ou seja, na capacidade que o usuário teria para assimilar os significados através dos sentidos ou da inteligência. Visto que o Guia é direcionado aos profissionais de saúde, a interpretação das informações com base em suas experiências seria ineficiente, como apresentado mais a frente. Dessa forma, a versão revisada do Guia incluiu um glossário contendo alguns termos usados provenientes do design (Figura 2). 


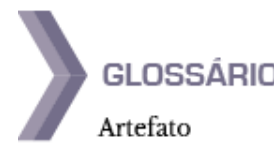

Artefato

Cíclico

Diagramaçāo

Design da Informaçāo

O termo é relacionado a um produto derivado de uma soluçāo em design. Podendo ser fisico, como um MEI, ou virtual, como uma interface gráfica para computadores.

Em metodologia de design, fala-se que quando há uma representaçāo cíclica nas etapas de desenvolvimento, é possivel que a mesma etapa acontece mais de uma vez dentro do mesmo processo até se chegar a um resultado satisfatório.

Ato de organizar espacialmente os elementos visuais que compōem determinada página.

A área do conhecimento que busca por meio da análise, planejamento, apresentaçāo e compreensāo dos conteúdos informacionais, conceber soluçōes visuais constituídas por significados objetivos e de simples associaçāo para os usuários em diferentes suportes.

Design Gráfico

Área do conhecimento que se utiliza da manipulaçāo visual e espacial de elementos visuais (signos, símbolos, textos, ilustraçōes, fotos, etc.) para conceber artefatos visualmente interessantes e funcionalmente compreensiveis pelos usuários.

Família Tipográfica

Conjunto de fontes com as mesmas características estilísticas fundamentais, porém apresentadas com variaçōes de espessura, largura, altura e outros detalhes.

Feedback

Em design, os feedbacks sāo diretamente relacionados às etapas da metodologia de

Figura 2 Glossário de termos do design na versão revisada do Guia. Fonte: Do autor.

Já no item IV, foi sugerido que algum conteúdo sobre utilização de cores no texto fosse incluído. E, embora as cores tenham abrangência quando são referidas como um possível atributo manipulável dos elementos visuais, optou-se por abordá-las considerando a representação de seus possíveis significados (Figura 3), ou seja, das representações de sensações que elas podem causar segundo a psicologia das cores (Heller, 2012). 


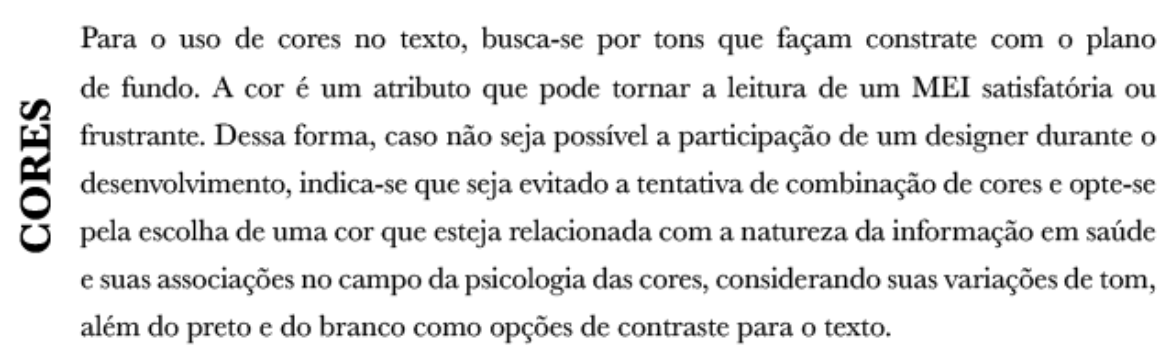

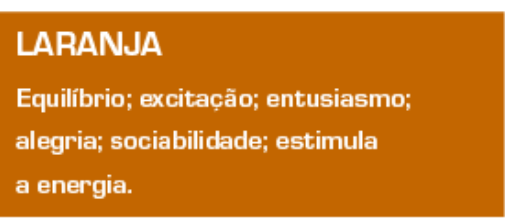

VERDE

Equilibrio; estabilidade; possibilidade; tranquilidade; crescimento; vitalidade; fertilidade.

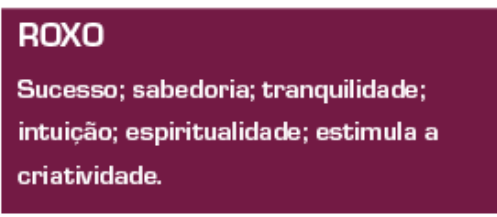

Figura 3 Indicação sobre o uso de cores. Fonte: Do autor.

Também foi visualizado pelo pesquisador, que o uso de um círculo cromático exemplificando possíveis combinações de cores, assim como quais combinações deveriam ser evitadas, acarretaria em um conteúdo muito voltado às responsabilidades do designer. Orientou-se dessa maneira, que os profissionais de saúde buscassem não ousar em muitas combinações de cores, mas escolhessem uma única cor relacionada com a natureza da informação em saúde, assim como suas tonalidades, além do preto e do branco para contrastar com o fundo.

Com outra perspectiva, o item $\mathrm{V}$ indica a presença de orientações acerca do redimensionamento de imagens. Segundo o juiz, seria interessante citar informações técnicas do design, como evidenciado em sua sugestão: "É importante frisar que as imagens utilizadas na elaboração dos impressos estejam na resolução de 3oodpi e convertidas na escala de cores CMYK, além de comentar que o redimensionamento das imagens pode causar efeitos não desejados."

A proposta foi acatada, mas readequada para o entendimento do profissional de saúde. Sabendo-se que muitos dos MEIs são elaborados e impressos no próprio local de atuação do profissional, torna-se mais válido orientar-lhe que as imagens não devam ser 'esticadas ou achadas', além de indicar caminhos para coleta de imagens em alta resolução. Nos casos que sejam necessários grandes tiragens em gráficas offset, os detalhes técnicos podem ser ajustados pelo impressor.

O item VI, relacionado a representação de expressões para promover identificação dos usuários através de cartoons, também recebeu sugestões. Uma das juízas recomendou que as informações 
fossem revistas, pois são controversas e carecem de fomento científico. A partir disso reviu-se este item refletindo que o uso de cartoons pode ser estratégia imagética consciente promovendo identificação do usuário para com o conteúdo do MEI.

Acerca dos cartoons , Freitas (2013) descreveu que cartoons veiculados em alguns MEIs traziam traços infantis sendo que o público alvo eram adultos. Assim a simplificação da complexidade de detalhes possa remeter ao imaginário de metáforas visuais das crianças e interpretados de forma literal por adultos em todas as situações de uso.

McCloud (1994) discorre que o poder do cartoon, em parte, é o poder de identificação, pois quando o usuário observa uma imagem detalhada, similar a uma pessoa no mundo real, ele a percebe, provavelmente, como um personagem particular; mas a representação simplificada, com pequena quantidade de detalhes, permite uma generalidade na identificação (Figura 4).

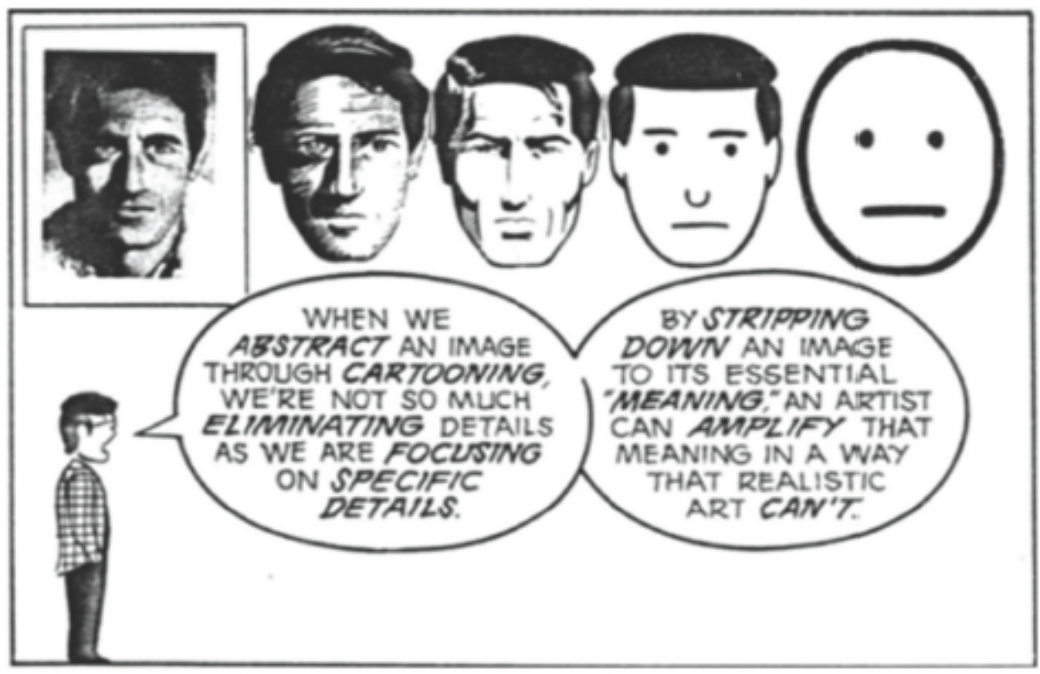

Figura 4 Transição pictórica. Fonte: McCloud (1994). Fonte: Do autor.

Porém, destaca-se que as estilizações exageradas ou excessiva simplificação, podem levar a falhas de interpretação ou confusões, a depender da ação/gesto representado na ilustração (Schumacher, 2011).

Sendo assim, Darras (2004) comenta acerca das propriedades figurativas das ilustrações que se enquadram no que o autor chama de nível básico de identificação, onde a representação figurativa deve conter padrões consensuais do que se é conhecido na vida real, através de traços abstratos.

Destaca-se ainda que um dos objetivos do Guia é reduzir os danos causados pelo uso inadequado de tais representações visuais e não resolver a equação em definitivo. Limitou-se assim, a abordagem dessa estratégia imagética para representar emoções, além de outras indicações introdutórias (Figura 5). 

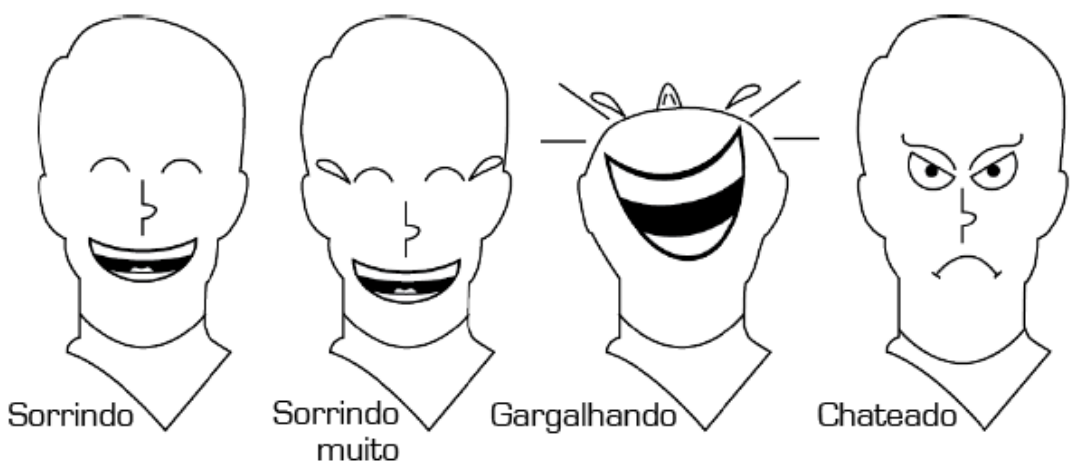

Figura 5 Trecho do Guia para orientação do uso de cartoons para representar emoções. Fonte: Do autor.

Acerca das indicações do item VII sobre a disposição da leitura dos quadros nas SPPs, foi observado que a lógica habitual ocidental de leitura da esquerda para direita e de cima para baixo, parecia entrar em conflito com o que foi apresentado. A recomendação procede pelas designações de programação visual de Vestergaard \& Schroder (2004), onde os autores consideram que a observação e decodificação dos elementos que compõem a página na cultura ocidental, vem de origem judaico-cristã, onde desde de cedo o indivíduo aprende o costume da leitura diagonal do canto superior esquerdo da página até o canto inferior direito. Assim, a modificação de leiaute foi realizada (Figura 6).

\section{ANTES}

\section{Ex.2}
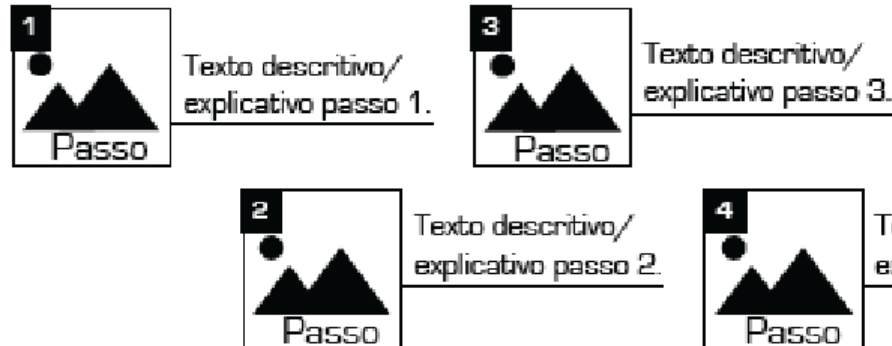

Texto descritivo/ explic:ativo passa 2

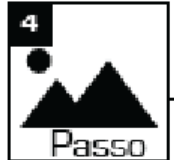

Texto descritivo/ explicativa passo 4.

\section{DEPOIS}
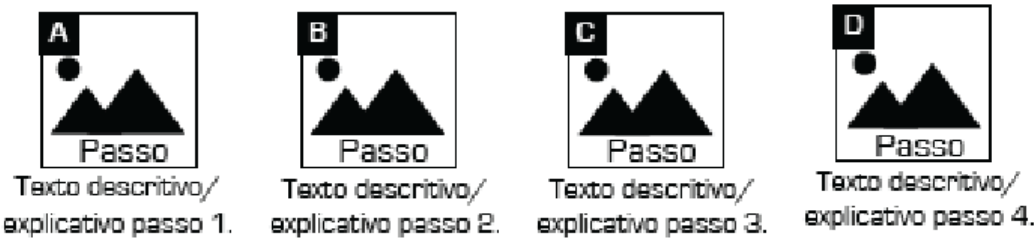

Figura 6 Exemplo de disposição dos quadros nas SPPs. Fonte: Do autor.

Já o processo metodológico para desenvolvimento de SPPs proposto por Spinillo (2000), necessitou ser readaptado e ramificado 
para uma compreensão mais adequada de acordo com pontos sinalizados na no item VIII.

Destaca-se que nenhuma das técnicas previstas originalmente para coleta de informações ou definições nas etapas de desenvolvimento foram modificadas. No entanto, descritores e perguntas norteadoras foram incluídas com base nas fundamentações teóricas originais de Spinillo (2000), para dar possibilidade de um relacionamento mais eficiente aos indivíduos envolvidos no processo de elaboração.

O indício foi levantado por um juiz do design que parecia não ter conhecimentos específicos acerca de SPPs, como demonstra o trecho: "Particularmente, tenho pouco a contribuir sobre o desenvolvimento das SPPs [...] acho válido que os passos presentes na metodologia sejam melhor esclarecidos."

Ao invés do pouco conhecimento sobre o assunto fragilizar a validação do conteúdo por um dos juízes, acabou por se tornar um apontamento de grande valia, pois a adaptação do processo metodológico se estenderá ao seu conhecimento e as competências dos profissionais de saúde (Figura 7).

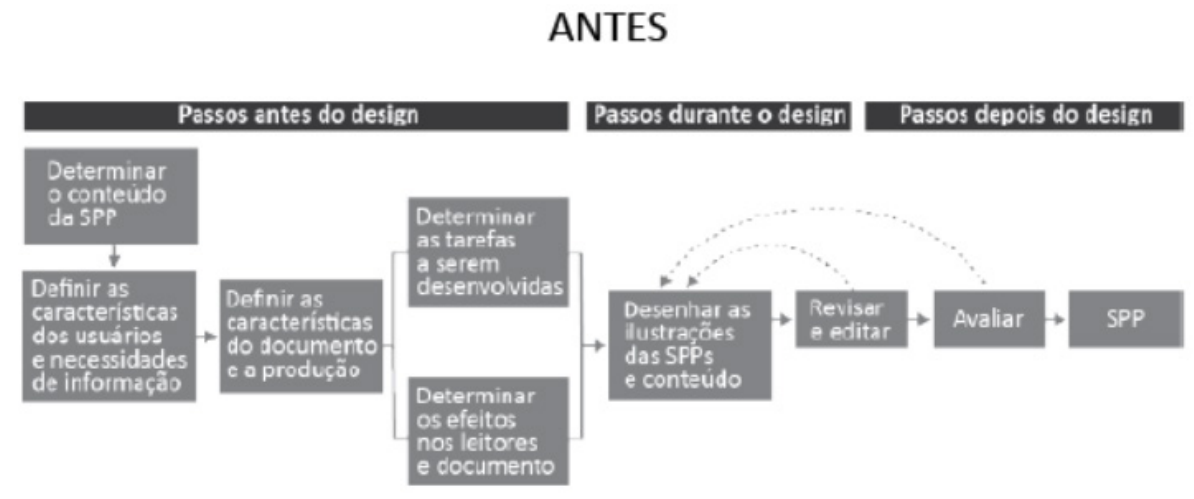




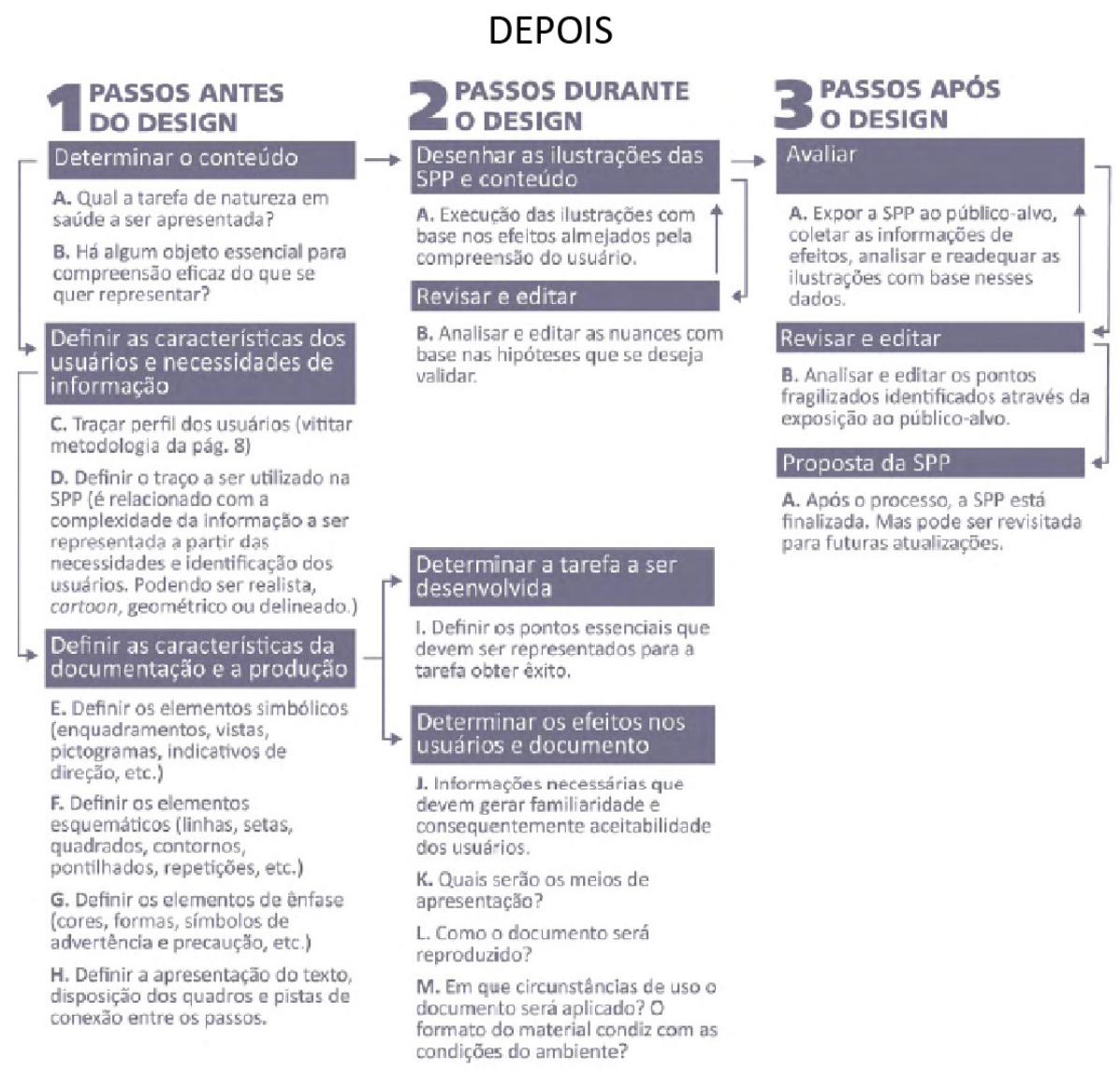

Figura 7 Comparação entre os processos metodológicos das SPPs nas duas versões do Guia. Fonte: Do autor.

Já os itens IX a XII, são alusivos aos ajustes no conteúdo de leiaute. Embora originalmente não previsto para como parte do Guia, durante seu desenvolvimento, viu-se a necessidade de indicativos de pelo menos quatro princípios básicos de design adaptados da Gestalt, sendo: proximidade, alinhamento, contraste e repetição. Sua escolha se deu como hipótese do pesquisador que seriam facilmente compreensíveis e plausíveis de uso pelos profissionais de saúde (Figura 8). 
ANTES

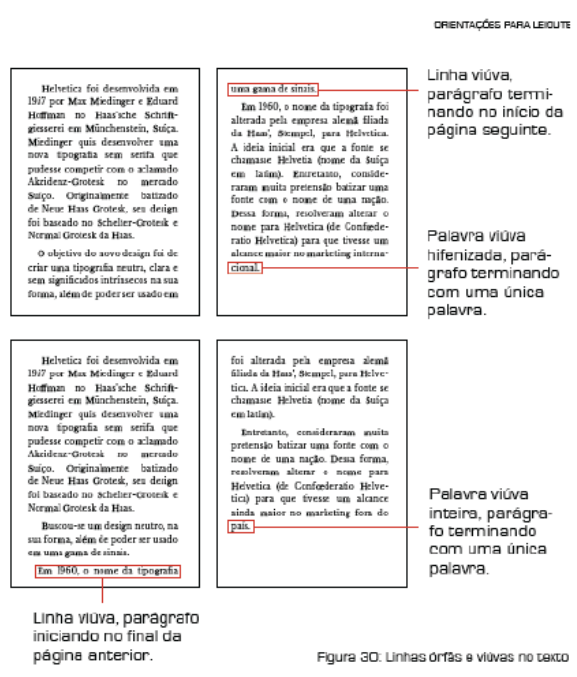

DEPOIS

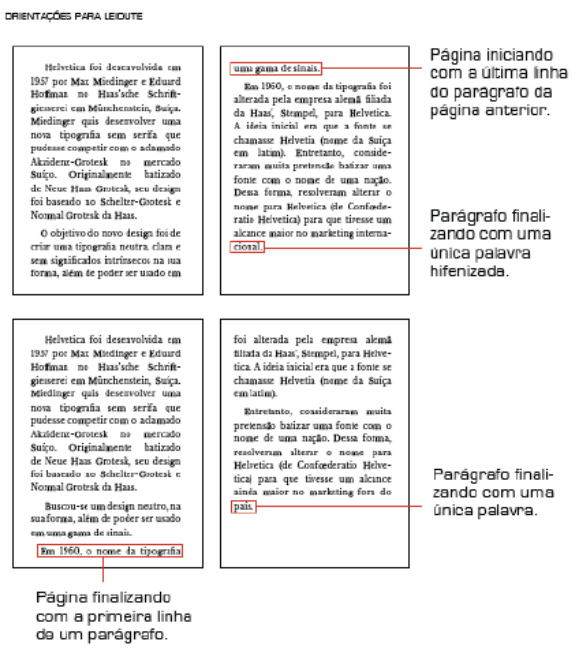

Figura 8 Comparação entre orientações de leiaute nas duas versões do Guia. Fonte: Do autor.

Pontuou-se também acerca do uso do princípio de repetição, que embora crie uma unidade visual no decorrer do MEI, pode também causar uma certa monotonia. O que oportunizou em orientações de como os elementos podem ser dispostos e variados para causar uma 'quebra' em sua exibição.

White (2005) destaca que quando cada página é diferente uma da outra, causa caos e confusão, tal como uso de cores, formas e texturas diferentes por página. Por isso é importante desenvolver um formato por conteúdo para disposição variada dos elementos e criar uma relação entre eles por meio de uma unidade visual identificável e compreensível, que crie um ritmo coeso (Figura 9).

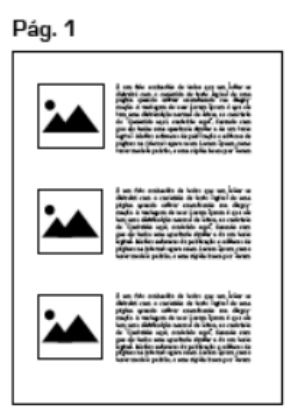

Pág. 3

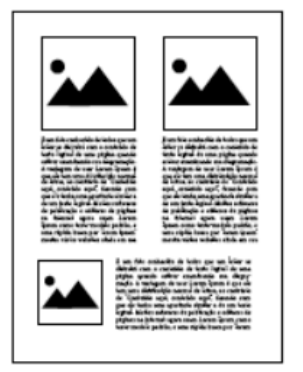

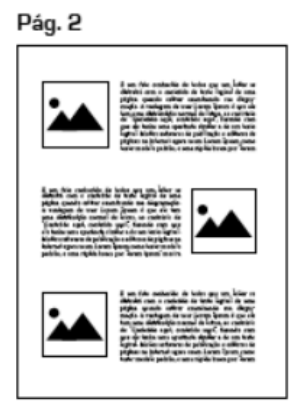

Pág. 4

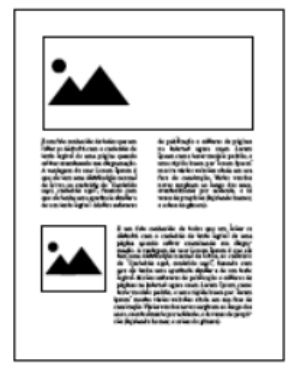

Figura 9 Trecho de recomendação sobre o princípio de repetição. Fonte: Do autor. 
Além disso, também foi sugerido que um link com mais informações de leiaute fosse disponibilizado caso seja de interesse do usuário do Guia se aprofundar sobre o assunto. Entretanto, acredita-se que competências de configuração e disposição geral de elementos seja de responsabilidade de um designer, por ser também necessário conhecimentos específicos na operação de softwares de manipulação. Dessa forma, a sugestão não foi considerada.

\section{Considerações Finais}

O método de validação de conteúdo proposto para o Guia, mostrou-se confiável para identificação de fragilidades e elaboração do material. Os comentários/sugestões elencados pelos juízes foram relevantes e fortaleceram as representações imagéticas no decorrer do conteúdo, a partir de orientações válidas acerca da disposição dos elementos na página. Estas contribuições possibilitaram um incremento essencial à melhoria da compreensão do conteúdo, supressão de termos técnicos e melhoria da leiturabilidade. Este fato corrobora com o IVC dos itens superior a 0,78 .

Foi possível reunir aspectos acerca da apresentação das informações sobre o prisma semântico, com destaque para o uso de imagens e esquemas gráficos. As considerações e abordagens propostas a partir da contribuição dos juízes trouxeram maior fundamentação na Linguagem Visual possibilitando maior aproximação entre conhecimento, teoria e prática de design para os profissionais de saúde ou para os não-designers que pretendem elaborar MEIs na área.

Destaca-se que a validação com os juízes, bem como aprofundamento do pesquisador na área, permitiu a elaboração de dois esquemas metodológicos, favorecendo a organização sistemática do pensamento científico em design. Além disso, algumas sugestões promoveram o enriquecimento em pontos antes não considerados pelo autor ou apresentados de forma inconsistente, pelo menos para a compreensão de quem habitualmente não se depara com a lógica do design. Desses pontos, merecem destaque a fluidez textual com que as informações eram apresentadas e alguns pontos de legibilidade das informações.

\section{Agradecimento}

Ao Conselho Nacional de Desenvolvimento Científico e Tecnológico (CNPq), pela bolsa concedida. 


\section{Referências}

Alexandre, N.M.C.; Coluci, M.Z.O. (2011). Validade de conteúdo nos processos de construção e adaptação de instrumentos de medidas. Ciência \& Saúde Coletiva, 16(7):3061- 3068. 2011.

Darras, B. (2004). Children's drawing and information design education. A semiotic and cognitive arpproach of visual literacy. In: Selected Readings of the Information Design International Conference 2003. Spinillo, C.G \& Coutinho, S.G. (Eds.) Recife. Sociedade Brasileira de Design da Informação, p.105-118.

Freitas, R.F. (2017). Construção e Validação de um Guia para elaboração de Materiais Educativos Impressos para Saúde: contribuições do Design da Informação. Tese de Doutorado não publicada. Universidade Federal de Pernambuco, Recife.

Freitas, R. F. (2013). Prevenção às IST/Aids e a recepção das mensagens em meios impressos. Universidade Federal de Pernambuco. Dissertação de mestrado não publicada, 2013.

Heller, E. (2012). A psicologia das cores: como as cores afetam a emoção e a razão. São Paulo: GG Brasil.

Horn, R. (1998). Visual Language: Global communication for the 21st century. Bainbridge Island, WA: MarcoVU, Inc.

Lopes, M.T; Barbosa, N.C.P. \& Coutinho, S.G. (2012). Metodologia de design e a prática pedagógica na sala de aula: a construção inicial de uma Matriz de Metodologias Contributivas. 10ํㅡㄹ Congresso Brasileiro de Pesquisa e Desenvolvimento em Design, São Luís (MA).

Mccloud, S. (1993). Understanding comics: the invisible art. New York: Paradox press.

Munari, B. (1981). Das coisas nascem coisas. São Paulo: Martins Fontes.

Pasquali, L. (2010). Testes referentes a construto: teoria e modelo de construção. In: L. Pasquali (Org.), Instrumentação psicológica: Fundamentos e práticas. p.165-198. Porto Alegre: Artmed.

Polit, D.F.; Beck, C.T. (2011). Fundamentos da pesquisa em enfermagem: avaliação de evidências para a prática de enfermagem. $7^{\text {a }}$ ed. Porto Alegre: ArtMed.

Pettersson, R. (2010). Information Design: Principles and Guidelines. Journal of Visual Literacy, vol. 29, n.2, 167-182.

Schumacher, P.C. (2011). The design of pictorical assembly instructions. Thesis submitted for the degree Doctor of Philosophy of the Astralian National University. December.

Spinillo, C.G. (2010). An analytical approach to procedural pictorial sequences. Tese de doutorado não publicada. Department of Typography \& Graphic Communication. The University of Reading.

Twyman, M. (2002). Further thoughts on a schema for describing graphic language. 1st Internacional Conference on Typography \& Visual Communication History, Theory, Education. University of Macedonia Press, Thessalonniki, Greece.

(1979) A schema for the study of graphic language. In: Processing of visible language. Editado por Paul A. Kolers, Merald E. Wrolstad \& Herman Bouma. Nova York \& Londres: Plenum Press, vol.1, p.117-150. 
Vestergaard, T.; Schroder, K.C. (2004). A linguagem da Propaganda. São Paulo: Martins Fontes.

White, J. V. (2005). Edição e Design. São Paulo: JSN.

\section{Sobre os autores}

\section{Ranielder Fábio de Freitas}

<ranielderfabio@hotmail.com>

Doutor em Design, Núcleo de Comunicação e Artes, UniFanor, Brasil

\section{Hans da Nóbrega Waechter}

$<$ hnwaechter@terra.com.br>

Doutor em Comunicação Audiovisual, Departamento de Design, UFPE, Brasil

\section{Solange Galvão Coutinho}

<solange.coutinho@ufpe.br>

Doutora em Typography \& Graphic Communication, Departamento de Design, UFPE, Brasil

\section{Fabiane do Amaral Gubert}

<fabianegubert@hotmail.com>

Doutora em Enfermagem, Departamento de Enfermagem, UFC, Brasil

Artigo recebido em 02/10/2019, aprovado em 03/04/2020. 